\title{
NOTAS SOBRE A IDENTIDADE TAXONÔMICA E DISTRIBUIÇÃO DO ERMITÃO PROPAGURUS GAUDICHAUDII (DECAPODA: ANOMURA: PAGURIDAE)
}

\author{
Marques, M.S. ${ }^{1,}$; Ribeiro, F.B. ${ }^{1}$ \& Lima, D. ${ }^{2}$ \\ ${ }^{1}$ Universidade Federal do Rio Grande do Sul (UFRGS), Campus do Vale, Laboratório de Carcinologia. \\ ${ }^{2}$ Universidade Federal Fluminense (UFF), Campus de Gragoatá, Laboratório de Paleoecologia e Mudanças Globais.
}

*Autor correspondente: mari.smarques@hotmail.com

\begin{abstract}
O gênero Propagurus McLaughlin \& de Saint Laurent, 1998 é composto por cinco espécies caracterizadas por possuírem brânquias quadrisseriadas e pleurobrânquias rudimentares nos somitos torácicos V e VI. Propagurus gaudichaudii (H. Milne-Edwards, 1836) é uma espécie endêmica da América do Sul, previamente registrada no Brasil, Uruguai, Argentina e Chile. Os registros na costa brasileira foram resultantes da expedição promovida entre 1968-1974 pelo Grupo Executivo do Desenvolvimento da Indústria da Pesca (GEDIP) do Instituto Oceanográfico da Universidade de São Paulo (IOUSP). Tal projeto realizou um levantamento do potencial pesqueiro da plataforma continental entre os municípios de Torres (RS) e Maldonado (Uruguai). Este trabalho tem como objetivo revisar a identidade taxonômica e a distribuição geográfica de P. gaudichaudii por meio dos espécimes depositados na Coleção de Crustáceos da Universidade Federal do Rio Grande do Sul (UFRGS) e do Museu de Zoologia da Universidade de São Paulo (MZUSP), além de informações disponíveis na literatura. Os exemplares foram ilustrados com um estereomicroscópio com câmara clara acoplada e mensurados em relação ao comprimento do escudo cefalotorácico (CEC). Ao todo, foram analisados nove espécimes, sendo cinco machos e quatro fêmeas (variando de 9,2 a $20.5 \mathrm{~mm}$ CEC). A mandíbula e os pereópodos 4 e 5 foram ilustrados e descritos pela primeira vez. A análise do material revelou que os registros de $P$. gaudichaudii para o Brasil eram incorretos, restringindo a distribuição da espécie para o Uruguai, Argentina e Chile, sendo os limites norte e sul de distribuição as localidades de Maldonado $\left(34^{\circ} \mathrm{S}\right)$ e o Estreito de Magalhães $\left(53^{\circ} \mathrm{S}\right)$, respectivamente.
\end{abstract}

Palavras-chave: taxonomia, biogeografia, Brasil, Paguroidea, Atlântico ocidental.

Financiamento: CAPES, CNPq. 